\title{
Present Status of Plasma-Wall Interactions Research and Materials Development Activities in the U.S.
}

\author{
Y. Hirooka and R.W. Conn
}

UCLA-PPG-\#1252 August, 1989

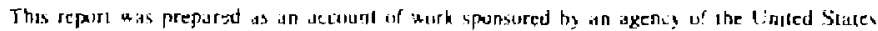

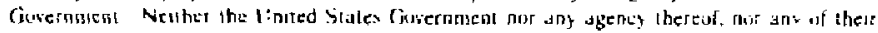

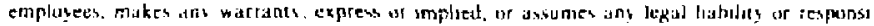

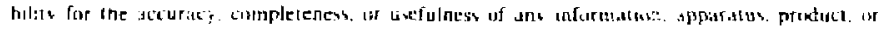

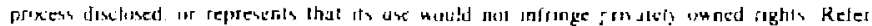

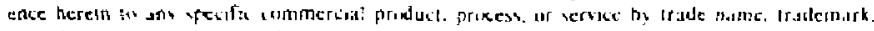

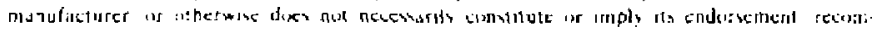

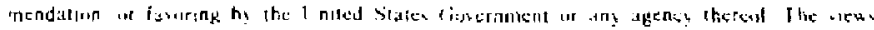

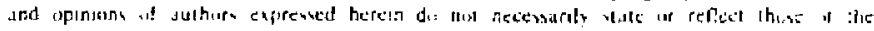

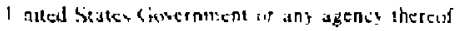

Institute of Plasma and Fusion Research

University of Califoria, Los Angeles

Los Angeles, CA 90024 


\title{
Present Status of Plasma.Wall Interactions Research and Materials Development Activities in US
}

\author{
Y. Hirooka and R.W.Conn \\ Institute of Plasma and Fusion Research \\ University of Califomia, Los Angeles \\ Los Angeles, CA90024
}

\section{Introduction}

It is well known in the fusion engineering community that the plasma confinement performance in magnetic fusion devices is strongly affected by edge-plasma interactions with surface comp onents. These plasma-marerial interactions (PMI) include fuel particle recycling and impurity generation both during normal and off-normal operation. To understand and then to control PMI effects, considerable effor thas been made, paricularly over the last decade in US, supported by Department of Energy, Division of Development and Technology. Also, because plasma-facing components are generally expected to receive significant amount of hint due to plasma bombardment and run-away electrons, materials must tolerate high-heat fluxes (HHF). The HHF-component research has been conducted in parallel with PMI research. One strong motivation for these research activities is that DT-buring experiments are currently planned in the Tokamak Test Fusion Reactor (TFTR) in early 1990s [1].

Several different but mutually complementary approaches have been taken in the PMI + HHF research. The first approach is to conduct PMl experiments using toroidal fusion devices such as TFTR. The second one is to simulate elemental processes involved in PMI using ion beams and electron beams etc. The last one but not 'east is to use nontokamak plasma facilities. Along with these laboratory activities, new materials have been developed and evaluated from the PMI+HHF point of view. In this paper, several major $\mathrm{PMJ}+\mathrm{HHF}$ research facilities in US and their activities are briefly reviewed. 


\section{PMI+HHF Research Activities}

1. In-tokamak PMI experiments

In-tokamak experiments are probably the most direct approach to understand edgeplasma interactions with materials. However, it is generally difficult to obtain dedicated machine time for PMI experiments in major tokamaks because obviously the highest priority goes to plasma confinement experiments. Also, deposition probe experiments, for example, may disturb the plasma confinement depending on probe positioning. The difficulty seems to arise from both technical and non-technical processes at large confinement facilitjes. Details of experimental plans should be implemented well in advance, which is not always possible for many cases.

Despite of these unavoidable difficulties, Princeton Plasma Physics Laboratory (PPPL), Sandia National Laboratories at Livermore and Albuquerque (SNLL and SNLA) jointly conducted a variety of in-tokamak experiments using TFTR in assessing tritjum inventory for the DT-experiments [1]. These PMI experiments in TFTR drew attention from researchers at other major tok:maks such as the Joint European Torus (JET). These researchers included confinement physicists as well as surface physicists.

This PPPL-SNL collaboration has been recently extended to University of California, Los Angeles (UCLA) and University of Toronto for more thorough understanding of PMI effects in TFTR. Quarterly meetings of Materials Physic Group (MPG) consisting of researchers involved in this multi-institutional collaboration have been extremely valuable in exchanging unpublished data anc in stimulating research interest.

Perhaps one of the most outstanding contributions of the MPG researchers is the understanding of graphite wall pumping effects, leading to an improved confisement refereed to as "supershots [2]" in TFTR in 1986. These wall pumping effects observed in TFTR are considered due to (1) hydrogen trapping in the surface layer [31; (2) hydrogen co-deposition with carbon [4]; and (3) tempolal storage of hydrogen in graphite pore channels [5,6]. More recently, first comprehensive characterization of TFTR-redeposited carbon materials has been done at SNL and UCLA. The characterization effon include various surface analysis [7] and re-sputtering yield measurements [8]. These characteristics of redeposited materials have long been subject to endless discussion in the fusion community because it is experimentally difficult to reproduce the exact same redepos.tion condition in non-tokamak facilities. The results of characterization of TFTR-redeposits are believed to provide answers to several frustrating arguments. 
2. Ion, electron beams and outgassing experiments

In plasma-materials interactions, there are many elemental processes to be understood. Important among them are: (1) hydrogen recycling via implantation and reemission: and (2) erosion via sputtering or evaporation. The use of ion and electron bearns is reasonable to simulate and to understand these individual PMI events. Also, it is probably true that these beam facilities are easier to define experimental conditons and more flexible in machine time than tokamaks. As a result, bulk of the existing PMI-related data base is contributed by experimental work done by ion and electron beam facilities [9].

Major ion beam facilities are located at SNLA and SNLL, and are currently used for two major objectives: (1) simulation of plasma bombardment; and (2) ion beam surface analysis. The ion bombarding flux for these ion beam facilities typically ranges from $10^{14}$ to $10^{16}$ ions $\mathrm{cm}^{-2} \mathrm{~s}^{-1}$. Also, the ion bombarding energy tends to stay in the keV range in most cases. These conditions are similar to those seen at the first wall in contact with the scrape-off layer plasma. So, the ion beam facilities have been extensively used for the first category of applications. In the second category, one of the most outstanding ion beam applications is the in-air Proton Induced X-ray Emission spectrosocpy (PIXE, see Fig. 1) technique developed at SNLA [10]. Many plasma-facing graphite components from TFTR have been already analyzed non-distructively [1].

For HHF experiments, an electron beam facility: EBTS (see Fig. 2) located at SNLA has been exclusively used to evaluate various graphite materials under simulated disruption and run-away electron bombardment conditions. Significant amount of data has been produced by this electron beam facility as shown in Fig. 3 [11]. Also, many collaborative experiments have been actively conducted with Japanese institutions such as Institute of Plasma Physics, Nagoya (IPP, Nagoya). In some cases, however, the electron beam data is subject to discussion with respect to the depth of energy deposition because jons come to rest much sooner in solid than electrons at the same energy. To conduct better-defined HHF experiments, recently a high-power ion beam facility: IBTS has been built at SNLA. In this facility, actively cooled components tests can be done using a pressurized water circulating system. Major features of these facilities art listed in Table 1.

Outgassing experiments have been actively conducted at SNLL since graphite was used as the plasma-facing component in TFTR. The outgassing behavior of graphite is so complex that new research interest has been generated in the PMI community. The outgassing data base has been established, including various graphite materials by SNLL (see Fig. 4 )! 12 !. 
3. PMI experiments in non-tokamak nlasma facilities

\subsection{The TPX and PISCES-A facilities}

In most existing tokamaks, the impurity production is dominated by edge-plasma interactions with limiters and divertor plates. In these cases, the ion bombarding flux generally ranges $10^{17}-10^{18}$ ions $\mathrm{s}^{-1} \mathrm{~cm}^{-2}$ and also the ion bombarding energy varies from 100 to $400 \mathrm{eV}$. Obviously, these conditions are not easily attainable by ion beam facilities. Also, it is necessary to understand several plasma effects such as (1) plasma-driven permeation; and (2) redeposition associated with re-ionization followed by transport.

Under these circumstances, an RF plasma facility: Tritium Plasma Experiment (TPX, see Fig. 5) was built in 1982 at SNLL[13] and a reflex-arc discharge plasma facility: Plasma Interactive Surface Component Experimental Station-A (PISCES-A, see Fig. 6) was constructed in 1984 at UCLA [14]. Both of these plasma facilities are capable of generating steady-state plasmas. As to ion bombarding flux, TPX covers the orders: $10^{16}$. $10^{17}$ ions $\mathrm{s}^{-1} \mathrm{~cm}^{-2}$ and PISCES-A covers the orders: $10^{17}-10^{18}$ ions $\mathrm{s}^{-1} \mathrm{~cm}^{-2}$, together of which are believed to fill out the gap between the ion beam and in-tokamak experiments. Major features of these two plastna facilities are shown in Table 2.

The TPX facility can use tritum, meaning that tritum retention can be directly evaluated. Also, in-situ Auger electron spectroscopy (AES) can be performed. This facility has made a significant data base in terms of tritium retention in various graphites as shown in Fig. 7[15]. Using PISCES-A, due to the high plasma density and electron temperature, one can conduct materials erosion experiments in which the degree of redeposition is controllable between less than a few $\%$ and higher than $80 \%$ [16]. To date, PISCES-A still is the only non-tokamak facility that has experimentally demonstrated materials redeposition effects. Also, collaborative experiments have been actively conducted using PISCES-A [17].

In some cases, however, the experimental difficulty was pointed out for PISCES-A as opposed to TPX. For example, it is unavoidable to expose the material sample to the air before surface analysis. This can raise uncertainty of the surface analysis data because in general plasma-bombarded surfaces are extremely air-sensitive. Also, the PISCES-A vacuum system is not bakable so that the base pressure is of the order of $10^{-6}$ Torr for most cases. For better-defined materials experiments, one might need lower vacuum pressures. To improve on these experimental difficulties, a new plasma-surface interactions research facility: PISCES-B has been recently built at UCLA. 
A new plasma-surface interactions research facility: PISCES-B has recently been constructed at UCLA. A schematic diagram of the PISCES-B facility is shown in Fig. 8. and major features are summarized and compared with those of PISCES-A in Table 2. The facility consists of the following components: (1) steady-state plasma generator; (2) multiport plasma experimental chamber; (3) differentially pumped RGA; (4) swing \& linear sample manipulator, and (5) in situ AES-SIMS surface analysis station.

The vacuum chamber sections are all bakable and the base pressure of the order of $10^{-8}$ Torr is attainable by means of two turbo molecular pumps with a total pumping speed of $6000 \mathrm{l} / \mathrm{s}$. Also, the main experimental chamber has 10 Iine-of-site ports, all the axes of which point the sample position. These line-of-site vacuum ports are installed with optical equipment such as CID camera and infra-red pyrometers for surface temperature measurements. Two large $(8 \mathrm{~cm} \times 25 \mathrm{~cm})$ windows are specially designed for plasma spectroscopy measurements with a $1 . \mathrm{C} \mathrm{m}$ monochromator and an optical multi-channel analyzer (OMA).

The sample can be transpored in-between the main experimental chamber and the in situ surface analysis station using the swing-linear sample manipulator. The regular sample is a circular disk with a diameter of $5 \mathrm{~cm}$ and a thickness of $5 \mathrm{~mm}$. However, it is possible to load the main chamber with a sample as large as $30 \mathrm{~cm} \times 30 \mathrm{~cm}$.

The plasma generator in PISCES-B can sustain steady-state plasmas of hydrogen isotopes, helium, argon and nitrogen. Also, it has been found that PISCES-B can generaring a wider range of plasma density and electron temperature than PISCES-A. Similarly to PISCES-A, the intrinsic energy of ions generated in the PISCES-B plasma generator is around $\mathrm{l} \mathrm{eV}$ or less. Therefore, the ion bombarding energy is controlled by applying a negative dc bias to the sample, which is at the floating potential. The dc bias voltage can be as high as $500 \mathrm{~V}$. From the PMl-parameters listed in Table 2, PISCES-B is considered to be an excellent simulator of the divertor conditions in toroidal facilities such as ITER.

Using PISCES-B, first erosion experiments have recertly been conducted for boronized graphite as a candidate plasma-facing component material for ITER. The data is shown in Fig. 9. Notice that boronized graphite exhibis 30\% reduced erosion, relative to iso-graphites, from room temperature to $1300^{\circ} \mathrm{C}$. To evaluated carbon-alternative materials, other international collaborations are also in pregress with KFA-Jülich, NETteam and IPP-Nagoya. A schematic collaboration diagram is shown in Fig. 10. 


\section{Materials Development Activities}

One of the most crucial but expensive components of the PMI+HHF research is to develop materials that can meet the requirements for plasma-facing components. Ideally, the materials development should proceed in such a way that the production and test facilities iterate with feedback until the requirements are achieved. However, this process is not always possible, particularly if only industries can play a production role. Also, collaborations with industries can be sensitive when it comes to proprietary issues. In most cases, therefore, fusion materials development in US starts with testing materials listed in production catalogues. As a result, researchers in the fusion community must make a risky compromise in selecting the "best" material. Unfortunately, this seems to be the case in the C-C composites development for the CIT and ITER divertor applications /191.

Several exceptional cuses are briefly described here for readers' information. Argonne National Laboratory (ANL) should be considered as an exceptional institution in this regard since metallic materials production facilities are well equipped at least for the quantities needed for the PMI-related research. From 1980 to 1987, copper-lithium alloy development was conducted at ANL. These alloys are intended to be used as an actively cooled plasma-facing component that spontaneously bears a low-Z lithium layer on the surface via Gibbsian segregation. These alloys were also tested in the PISCES-A facility in 1986. It was found that the erosion yield of copper-lithium alloys was about a factor of 2-3 lower than pure copper [20]. Unfortunately, this finding was not sensational enough to draw attention from the fusion materials community because pure copper is known as an exuremely easy material to be sputtered, compared with other materials. Also, recent efforts on brazing materials development and analysis at SNLA deserve some compliments here. These brazing materials are intended to be used for contacting copper as the base metal and several plasma-facing materials such as graphite and tungsten [21]. In general, the development of special materials is such a time-consuming process that not all the induscries would even try unless a sizable market is guaranteed.

Another exceptional materials development activity has been in progress at UCLA in collaboration with a Japanese graphite materials manufacture (Toyo Tanso Co.). In this collaboration, boronized graphite is tested at the PISCES-B facility. The erosion and postbombardment outgassing data from UCLA will be implemented as the feedback information in the rext production process. Also, this boronized graphite collaboration has been recently extended to SNLL for tritium inventory measurements, SNLA for thermaJ shock tests and ORNL for neutron irradiation. 
IV. Summary

Major PMI+HHF facilities and their activities may be summarized as follows:

(1) UCLA PISCES-A: Edge-plasma physics experiments.

PISCES-B: Materials erosion experiments and in-situ AES+SIMS.

(2) SNLA EBTS: Electron beam facility high-heat flux experiments.

IBTS: Ion beam facility high-heat flux experiments.

Ion beam facilities for PIXE, NRA and RBS analysis.

(3) SNILL TPX: Tritium retention experiments.

LAMPE: Carbon+hydrogen co-deposition experiments.

(4) ORNL Outgassing facility for vacuum properties measurements of graphites.

RFTF: RF-plasma facility for wall conditioning experiments.

(5) HEDL HEBF: Electron beam tests in a hot cell for neutron activated materials.

Collaborations among these facilities and also with industries have been extremely effective in enhancing research activities (see Fig. 10). From a budget point view, these collaborations are strongly encouraged because normally the same facility for the same purpose is unlikely to be funded elsewhere. Also, it is believed to be important for researchers in the $\mathrm{PMI}+\mathrm{HHF}$ community to interact with those from confinement facilities such as TFTR and DIII-D. In short, the research activities are coordinated in such a way that institutional and individual expertise is appreciated and unnecessary competitions are avoided.

\section{Acknowledgements}

The authors would like to thank W.Gauster for useful discussions. This work is supported by the Office of Fusion Energy, U.S. Deparment of Energy under Contract No. DE-AT03-84ER52104. 


\section{References}

(1) H.F.Dylla and K.L.Wilson ed.. "Tritrum Retention in TFTR". Princeton Plasma Physics Laboratory and Sandia Repor, PPPL-2523, SANT 88-8212.

[2] K.W.Hill, V.Arunasalm et.al., Proc.lAEA 11 th Int.Conf.on Plasma Physics and Controlled Fusion Research, Kyoto, p. 207 (1986).

[3] W.R.Wampler and B.L.Doyle, J.Nucl.Mater. 162-164. 1025 (1989).

[4] W.L.Hsu and R.A.Causey, J.Vac.Sci.\&Technol.-A 5, 2768 (1987).

[5] Y.Hirooka, W.K.Leung et.al., Vac.Sci.\&Technol.-A 6, 2965(1988).

[6] Y.Hirooka, R.W.Conn et.al., J.Nucl.Mater. 162-164, 1004 (1989).

[7] B.Mills, D.A.Buchenauer et.al., J.Nucl.Mater, 162-164. 343 (1989).

[8] Y.Hirooka. A.Pospieszczyk et.al., Vac.Sci. \&Terhnol.-A 7, 1070 (1989).

[9] R.Behrisch (ed.) "Sputtering by Paricle Bombardment I and II", Springer-Verlag.

[10] B.L.Doyle, J.Vac.Sci.\&.Technol.-A, 3,1374 (1985).

[11] C.D.Crossman, N.B.Gilbenoson et.al. Fusion Technol 15, 127 (1989).

[12] A.E.Pontau adn D.H.Morse. J.Nucl.Mater. 141-143, 124(1986).

[13] R.A.Kerst, J.Nucl.Mater.103-104, 439(1981).

[14] D.M.Goebel, G.A.Campbell and R.W.Conn, J.Nucl.Mater. 111-112, 457 (1984).

[15] R.A.Causey, 162-164, 151(1989).

[16] Y.Hirooka, D.M.Goebel et.al., Nucl.Mater, 141-143, 1 193(1986),

[17] PISCES-Team, "PISCES Program, Plasma-Surface Interactions Research: Summary of Research 1988-1989", UCLA Repor PFG\# 1247.

[18] Y.Hirooka. R.W.Conn, et.al. "A New Plasma-Surface Interactions Research Facility: PISCES-B and First Materials Erosion Experiments on Boronized Graphite", to be presented at American Vacuum Scoiety 36th National Symposium, Boston (1989).

[19] J.Davis, Proc. of US-Japan Workshop P134, Hokkaido, Japan, Feb.1989.

[20] D.M.Goebel, Y.Hirooka, et.al., J.Nucl.Mater. 145-147, 61 (1987),

\{21] W.Gauster, Proc. of US-Japan Workshop P134, Hokkaide, Japan, Feb.1989. 
Table 1 High-heat flux test facilities at SNLA.

\begin{tabular}{|c|c|c|}
\hline HHF parameters & EBTS & IBTS \\
\hline Beam species & e-beam & $\mathrm{H}^{+}$beam \\
\hline Beam voltage (kev) & 30 & 40 \\
\hline Beam current (A) & 1 & 20 \\
\hline Total heat flux (kW) & 30 & 800 \\
\hline Sample size $\left(\mathrm{cm}^{2}\right)$ & up to 1800 & up to 100 \\
\hline Pulse duration (s) & 0.05 to continuous & up to 12 \\
\hline Target cooling & $\begin{array}{l}\text { Closed loop water } \\
\text { (50GFM at 300PSI) }\end{array}$ & $\begin{array}{l}\text { Closed loop water } \\
\text { (500GPM at } 1000 \mathrm{PSI})\end{array}$ \\
\hline Diagnostics & $\begin{array}{l}\text { IR pyrometer } \\
\text { Optical pyrometer } \\
\text { IR camera } \\
\text { RGA } \\
\text { Video camera }\end{array}$ & $\begin{array}{l}\text { IR pyrometer } \\
\text { Optical pyrometer } \\
\text { IR carnera } \\
\text { RGA } \\
\text { Video samera }\end{array}$ \\
\hline
\end{tabular}


Table 2 Non-tokamak plasma facilities for PMI experiments at SNLL and UCLA.

\begin{tabular}{|c|c|c|c|}
\hline PMl parameters & $\begin{array}{l}\text { TPX } \\
\text { (SNLL) }\end{array}$ & $\begin{array}{l}\text { PISCES A } \\
\text { (UCLA) }\end{array}$ & $\begin{array}{l}\text { PISCES-B } \\
\text { (UCLA) }\end{array}$ \\
\hline Plasma generation & $\begin{array}{l}\text { RF \& glow } \\
(200 W)\end{array}$ & $\begin{array}{l}\text { Reflex arc } \\
(40 \mathrm{~kW})\end{array}$ & $\begin{array}{l}\text { Reflex arc } \\
(50 \mathrm{~kW})\end{array}$ \\
\hline Plasma species & $\begin{array}{l}\mathrm{H}, \mathrm{D}, \mathrm{T}, \mathrm{He} \\
\mathrm{Ar}, \mathrm{N}, \mathrm{O}\end{array}$ & $\begin{array}{l}\mathrm{H}, \mathrm{D}, \mathrm{He} \\
\mathrm{Ar}, \mathrm{N}\end{array}$ & $\begin{array}{l}\mathrm{H}, \mathrm{\cap} \mathrm{He} \\
\mathrm{At} \sim \mathrm{N}\end{array}$ \\
\hline Mode of operation & Continuous & Continuous & Continuous \\
\hline Plasma density $\left(\mathrm{cm}^{-3}\right)$ & $10^{10}-10^{11}$ & $10^{31} \cdot 10^{13}$ & $10^{11} \cdot 10^{13}$ \\
\hline Electron temperarure (eV) & $3=7$ & 3.30 & $3-50$ \\
\hline $\begin{array}{l}\text { Ion bumbading flux } \\
\text { (ions } \mathrm{s}^{-1} \mathrm{~cm}^{-2} \text { ) }\end{array}$ & $10^{15}-30^{17}$ & $10^{17}-10^{18}$ & $10^{17}-10^{19}$ \\
\hline Target area $\left(\mathrm{cm}^{2}\right)$ & $10-20$ & $50-300$ & $50-700$ \\
\hline $\begin{array}{l}\text { lonization mean free path } \\
\text { for varbon redeposition }(\mathrm{cm})\end{array}$ & down to 100 & down to 1 & down to 0.5 \\
\hline Jon bombarding energy $(\mathrm{eV})$ & $\begin{array}{l}15-300 \\
(\mathrm{dc} \text { bias })\end{array}$ & $\begin{array}{l}10-500 \\
\text { (dc bias) }\end{array}$ & $\begin{array}{l}10-500 \\
\text { (dc bias) }\end{array}$ \\
\hline Base pressure (Tor) & $10^{-8}$ & $10^{-6}$ & $10^{-8}$ \\
\hline Operation press:dre (Tor) & $10^{-3}-10^{-2}$ & $10^{-4}-10^{-5}$ & $10^{-5}-10^{-3}$ \\
\hline Plasma \& surface diagnostics & $\begin{array}{l}\text { RGA } \\
\text { Langminir probe } \\
\text { In-situ AES }\end{array}$ & $\begin{array}{l}\text { RCA } \\
\text { Langmuir probe } \\
\text { OMA } \\
\text { Monochromator }\end{array}$ & $\begin{array}{l}\text { RGA } \\
\text { Langmuir probe } \\
\text { In-situ AES+SIMS } \\
\text { OMA } \\
\text { Monochromator } \\
\text { IR pyróneter } \\
\text { CID camera } \\
10 \text { bine-of-site ports }\end{array}$ \\
\hline
\end{tabular}




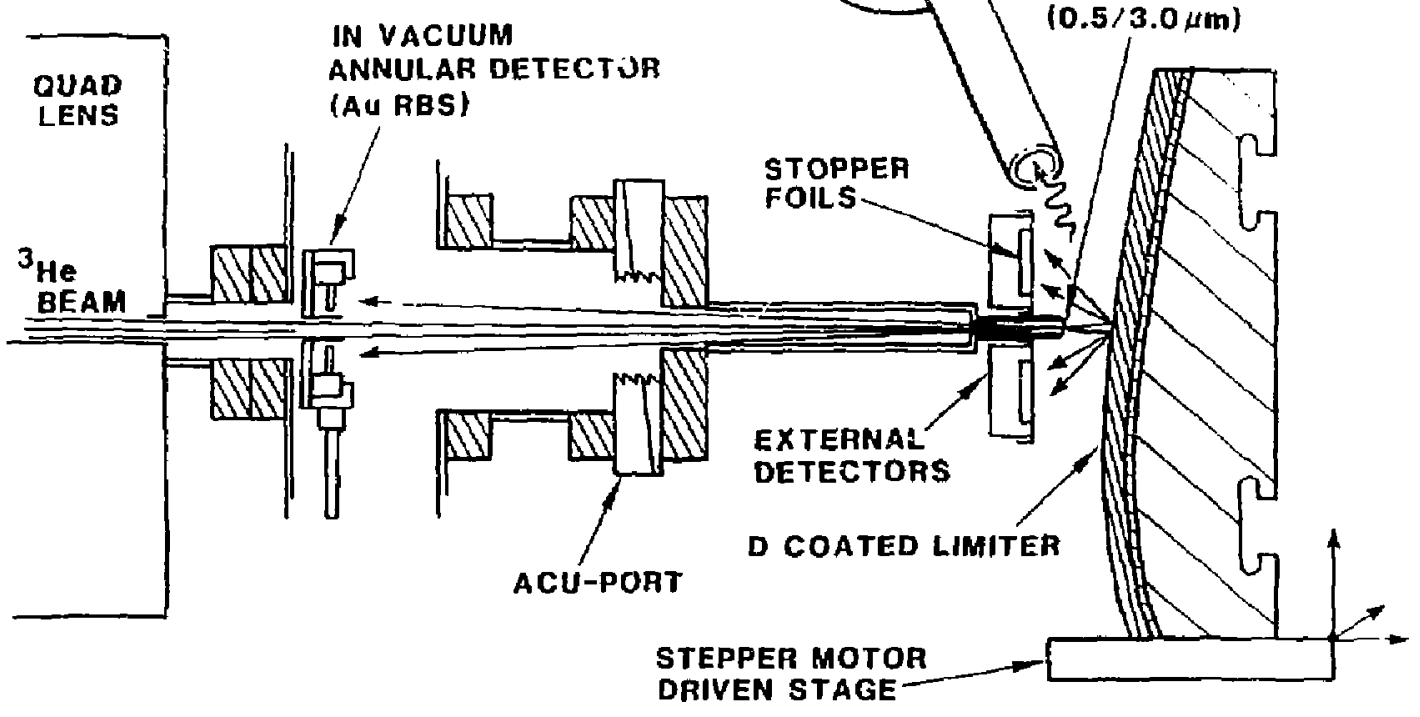

Fig. 1 A schematic illustration of in-air PIXE technique at SNLA. 


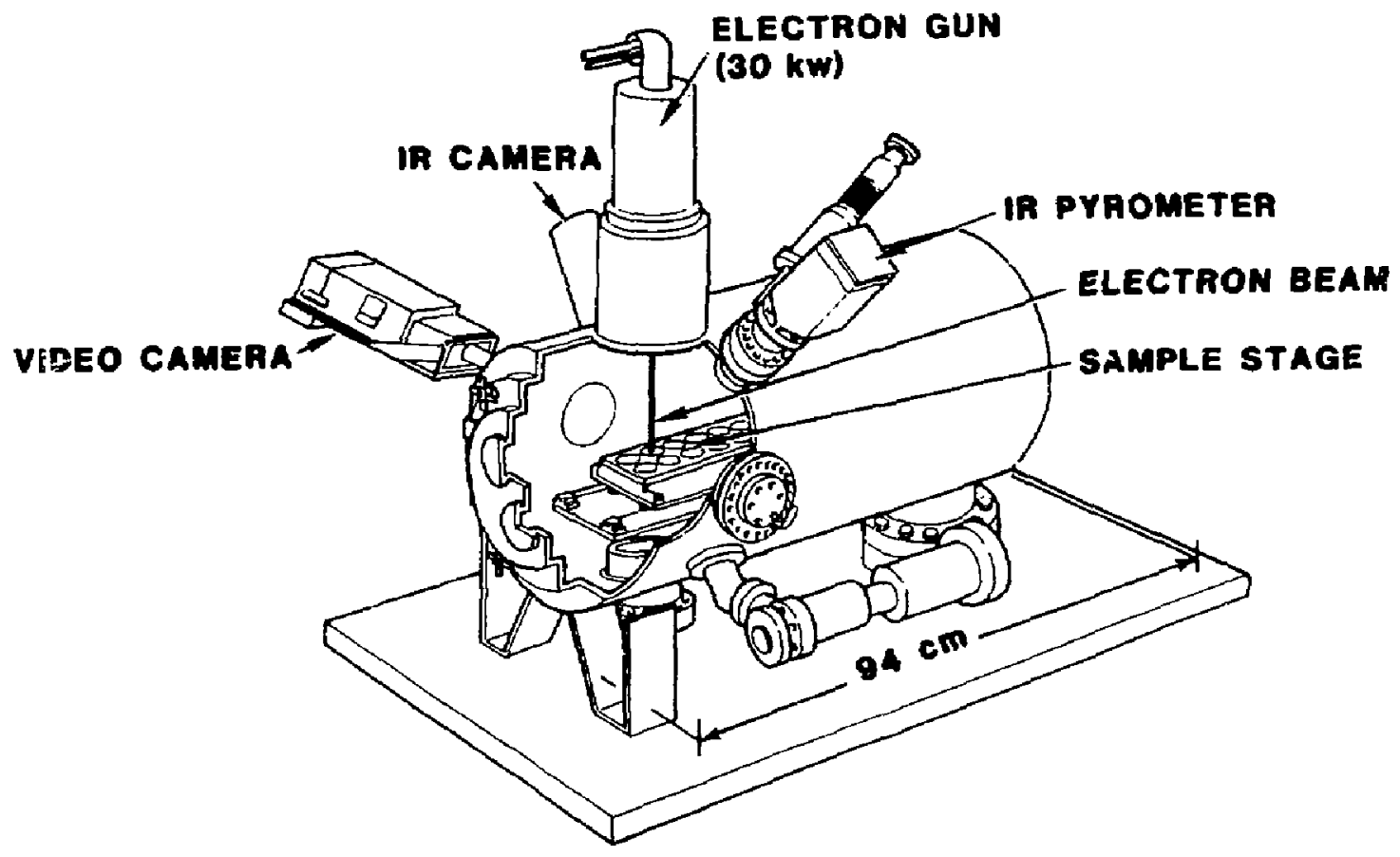

Fig. 2 A schematic diagram of Electron Beam Test Stand:EBTS at SNLA. 


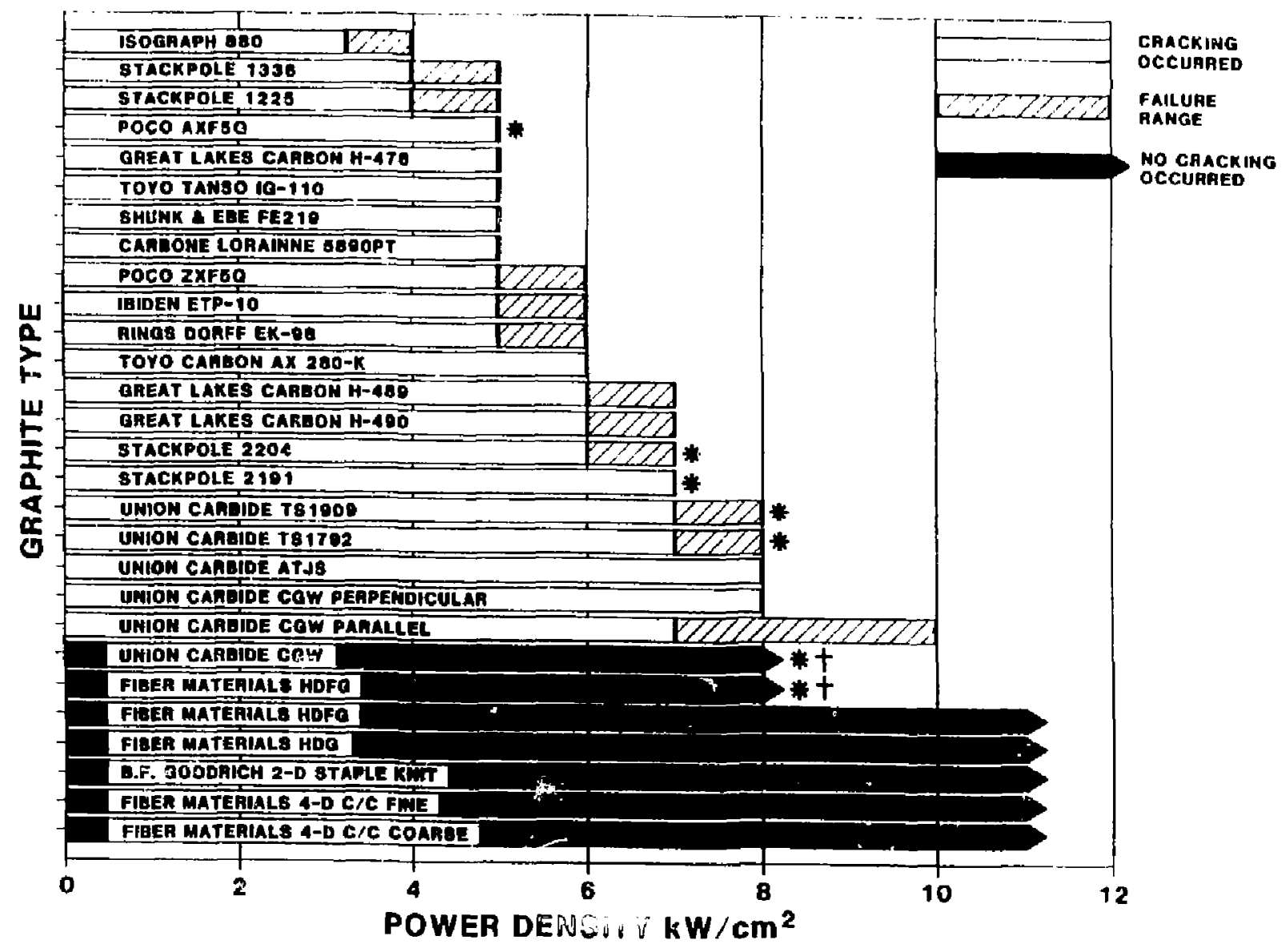

* samples hot cleaneo of outgassed

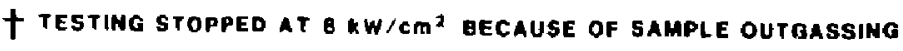

Fig. 3 Iligh heat flux test data base for various graphites (after Crossman et.ail. \{11\}). 


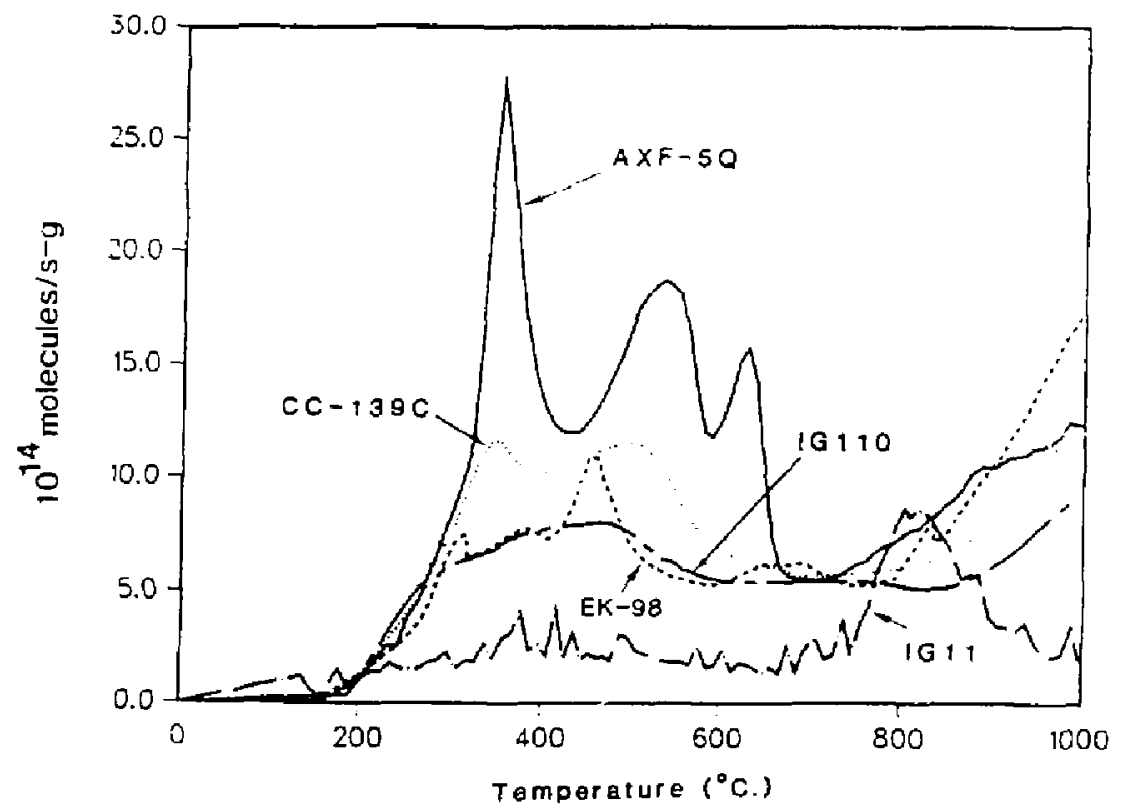

Fig. 4 Outgassing spectra for various graphites (after Pontau and Morse [12]). 


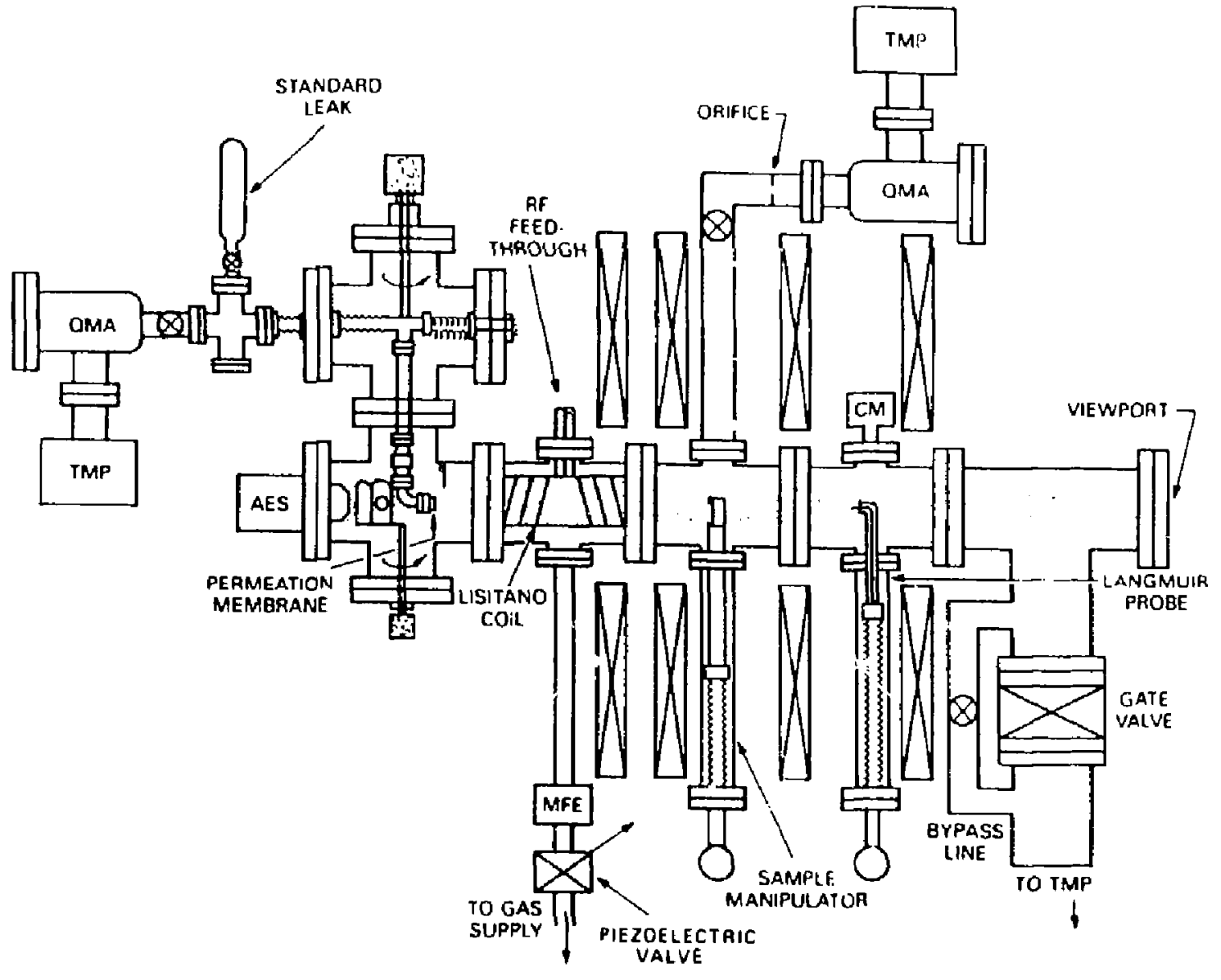

Fig. 5 A schematic diagram of the TPX facility at SNLLL. 


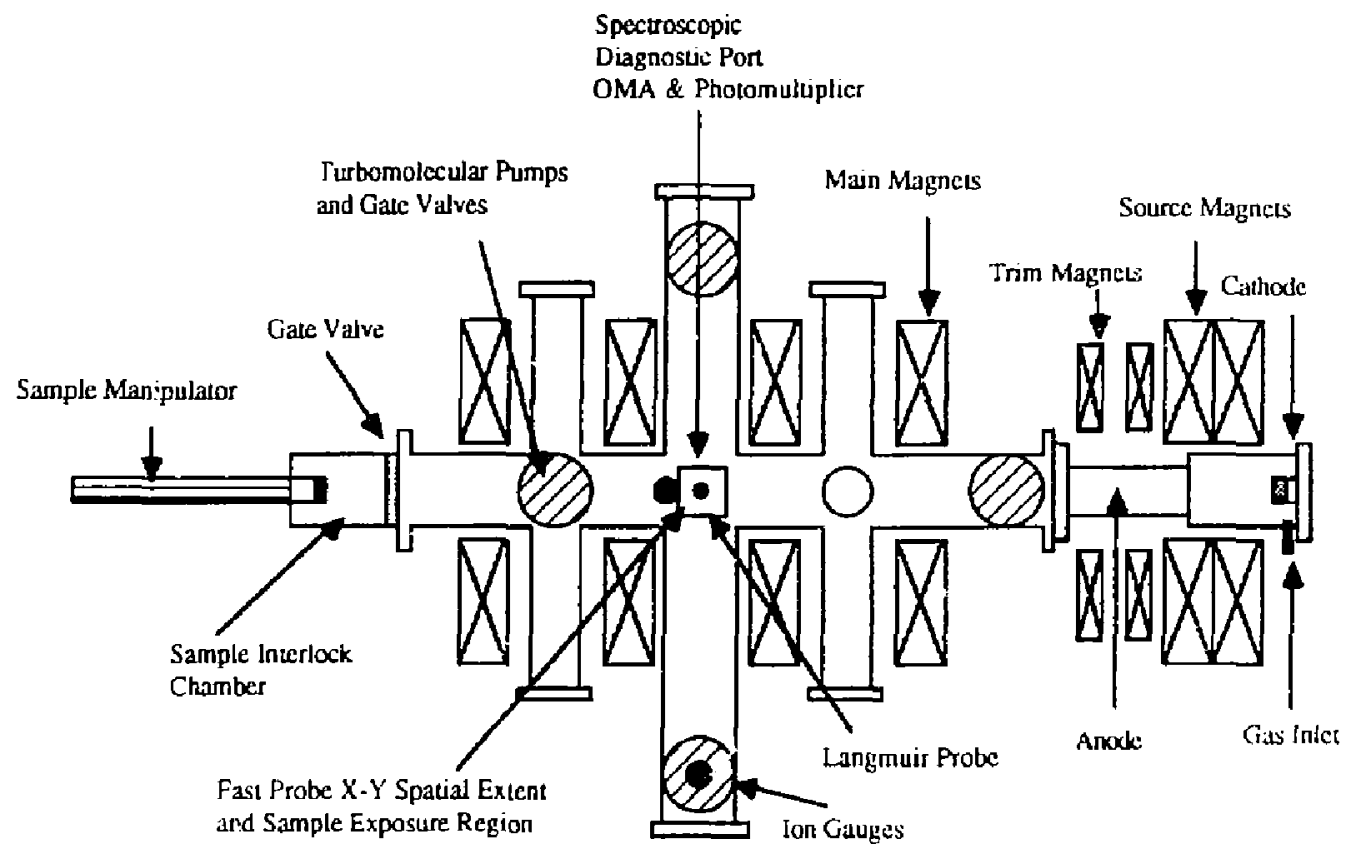

Fig. 6 A schematic diagram of the PISCES-A facility at UCLA. 


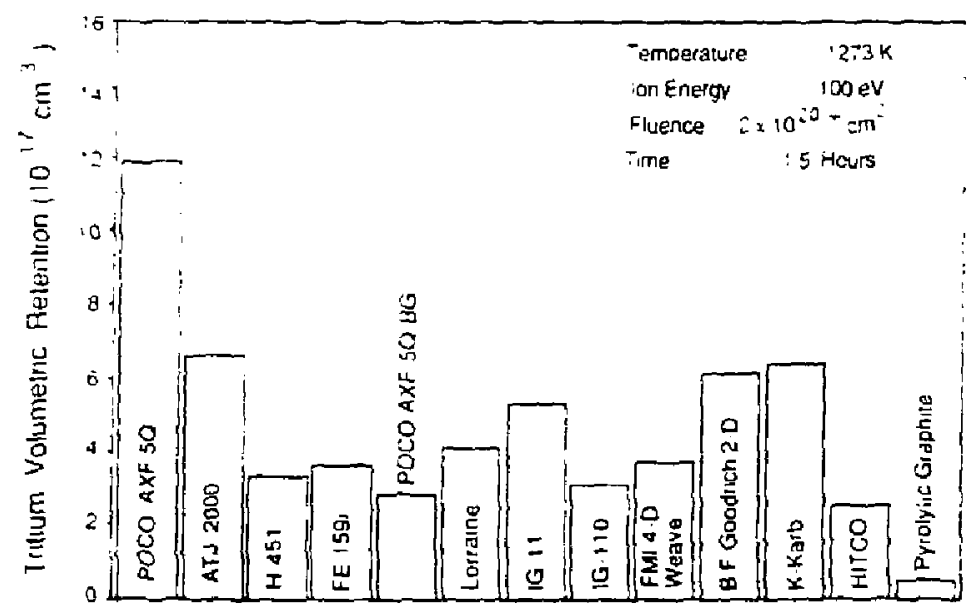

Fig. 7 Tritium inventory data for various graphites (after Causey (15]). 


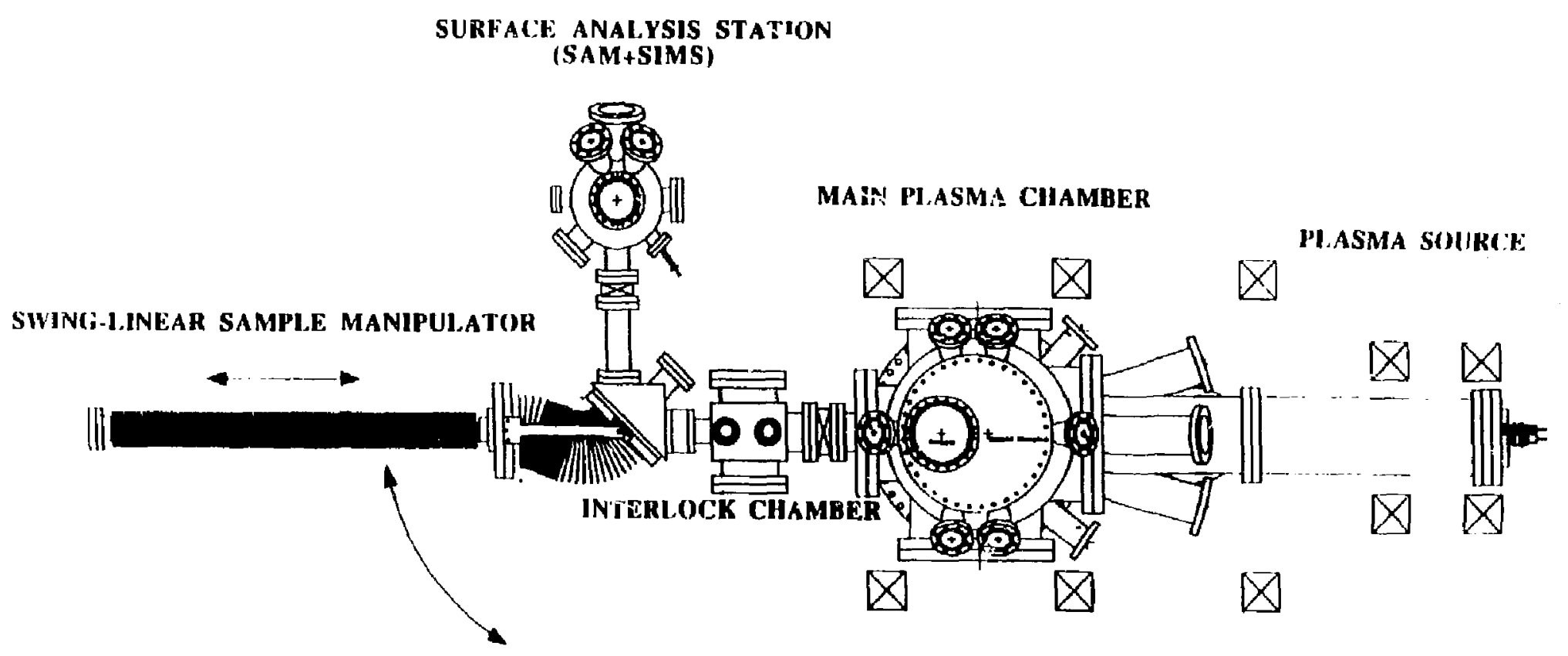

Fig. $8 \wedge$ schematic diagram of the PISCES-B facility at UCLA. 


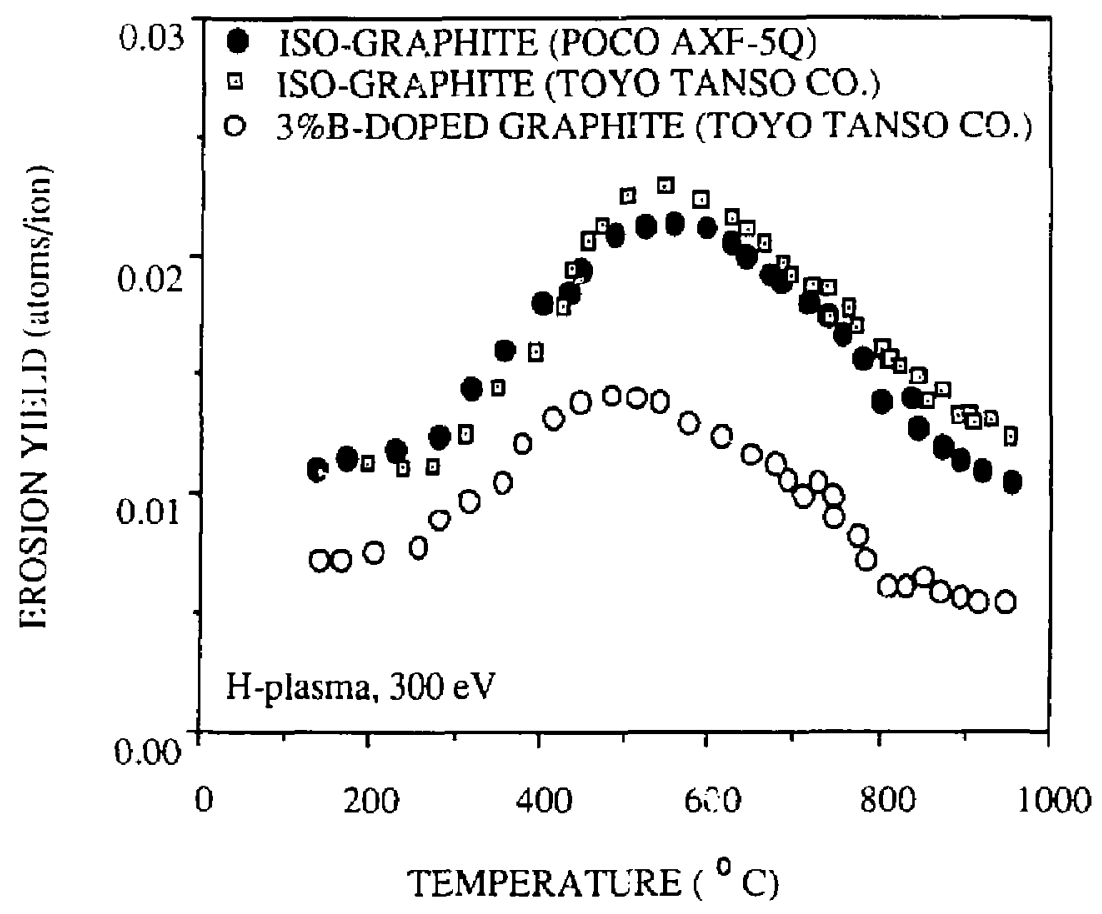

Fig. 9 Chemical sputtering of boronized graphite and iso-graphites (after Hirooka et.al. [18]). 


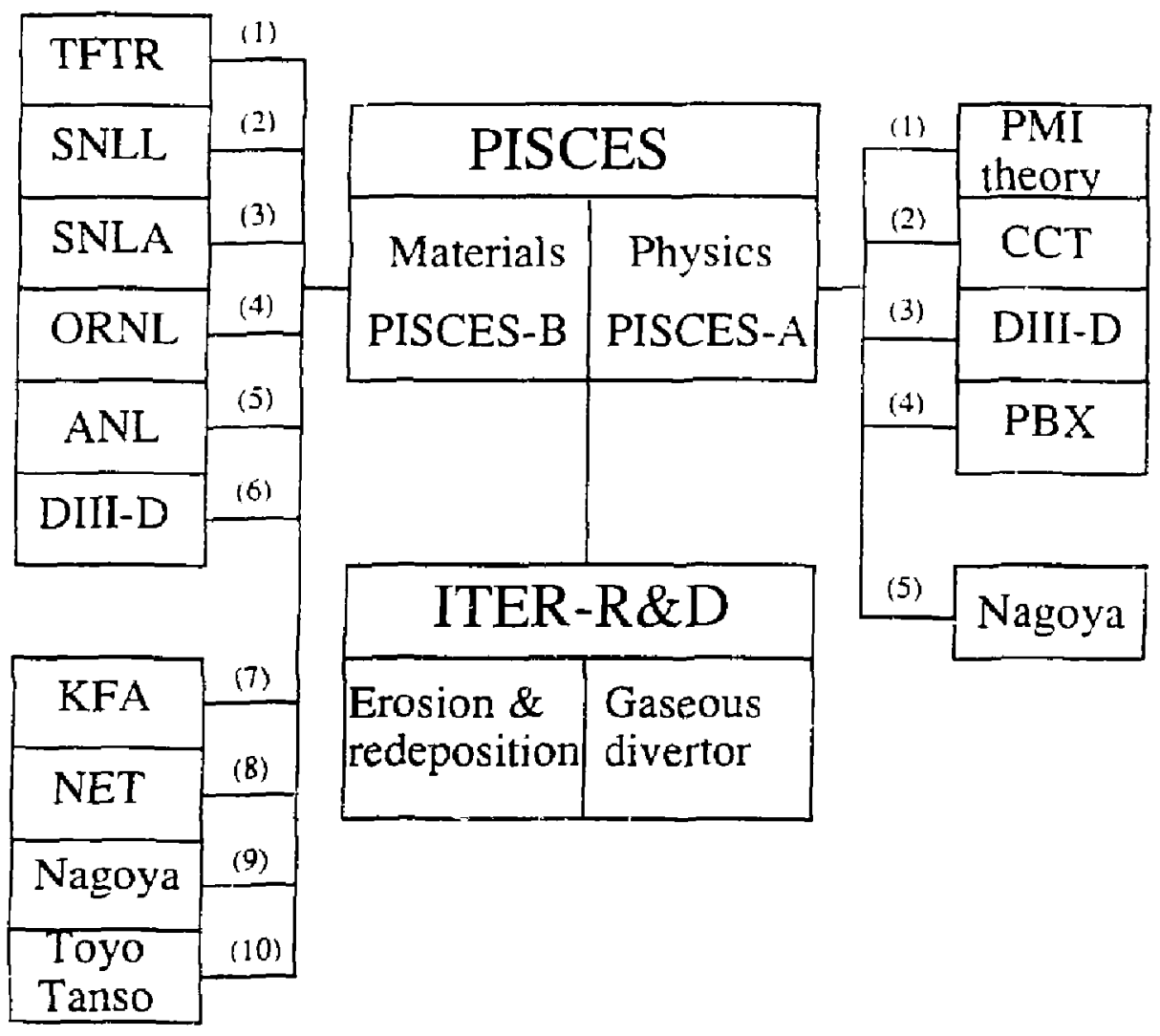

Matenals collaborations
(1) DT-Mareriats Physics Meecing
(2) B-doped graphite: T-inventory
(3) B-doped graphite: thermal shock
(4) B-doped graphite: nuclear properries
(5) He self-pumping
(6) Ceramic insulators tests for ADP
(7) TEXTOR graphite tile analysis
(8) NET-candidate materials test
(9) Al-Li alloy test
(10) B-doped graphite: production

Physics collaborations

(1) RF, biased iimiter analysts

(2) Biased divertor in CCT

(3) Biased divertor in DIII-D

(4) Biased diveror in PBX

(5) RF limiler

Fig. 10 A collaboration diagram of the PISCES-team for 1989-1990. 